\title{
Mechanical Properties and Control Rockburst Mechanism of Coal and Rock Mass with Bursting Liability in Deep Mining
}

\author{
Ming-tao Gao, ${ }^{1,2,3}$ Zhen-qi Song, ${ }^{1,3}$ Hui-qiang Duan $\mathbb{D}^{4},{ }^{4}$ Heng-qi Xin, ${ }^{2,3}$ \\ and Jian-quan Tang ${ }^{1}$ \\ ${ }^{1}$ College of Energy and Mining Engineering, Shandong University of Science and Technology, Qingdao 266590, China \\ ${ }^{2}$ Shandong Energy Xinwen Mining Group Co., Ltd., Taian 271200, China \\ ${ }^{3}$ National Engineering Laboratory of Coal Mine Filling and Mining, Taian 271019, China \\ ${ }^{4}$ School of Mining and Coal, Inner Mongolia University of Science and Technology, Baotou 014010, China
}

Correspondence should be addressed to Hui-qiang Duan; duanhuiqiang11@163.com

Received 10 September 2020; Accepted 23 September 2020; Published 10 October 2020

Academic Editor: Gang Zhou

Copyright ( 12020 Ming-tao Gao et al. This is an open access article distributed under the Creative Commons Attribution License, which permits unrestricted use, distribution, and reproduction in any medium, provided the original work is properly cited.

In order to study the mechanism of the dynamic disaster of rockburst in a deep coal mine and the prevention and control measures of weakening shock, the MTS815.03 servocontrolled rock mechanics test system is used to test the coal, rock, and combined specimens with the buried depth of nearly $1200 \mathrm{~m}$ in Xinwen Mining Area. And their mechanical properties, energy evolution, and bursting properties are studied and analyzed. The rationality of the test results is also verified by the in-situ engineering practice. The key conclusions are as follows: (1) There is a relation between the ratio of elastic modulus $E_{\mathrm{e}}$ before peak strength to descending modulus $E_{\mathrm{d}}$ after peak strength and the bursting properties. For the fractured coal, the descending modulus $E_{\mathrm{d}}$ is relatively small, and the $E_{\mathrm{e}} / E_{\mathrm{d}}$ is relatively large and presents progressive ductile failure with low probability and risk of rockburst. For the less fractured rock, the descending modulus $E_{\mathrm{d}}$ is relatively large, and the $E_{\mathrm{e}} / E_{\mathrm{d}}$ is relatively small and presents brittle failure, which is very similar to the characteristics of rockburst. (2) For the same type of rock, with the increase of confining pressure, the $E_{\mathrm{e}} / E_{\mathrm{d}}$ gradually increases, indicating the reduction of rockburst strength. Therefore, the greater the support strength provided to the surrounding rock surface of the roadway, the smaller the failure degree of rockburst. (3) With the increase of confining pressure, after peak strength, the elastic energy of coal specimens decreases slowly, and the dissipated energy increases slowly, indicating that the increase of confining pressure can effectively limit the energy dissipation and release after coal specimen failure. So, in the in-situ engineering practice, it is an important measure to improve the surface restraint and support strength of the coal roadway for reducing the occurrence intensity and probability of rockburst. (4) The combined measures of "the mining of double liberating seam + the implementation of largediameter pressure relief borehole in advance of working face" is the very effective way to eliminate the rockburst accidents of working face in a protected coal seam and has an important guiding significance for the safe mining of rockburst mine.

\section{Introduction}

China is rich in coal, but it has little gas and oil. In the past, coal has provided the main driving force for the rapid development of China's national economy. Now, although China is promoting the development of the new energy industry, the status of coal as the main energy in China will not change for a long time. With the continuous increase of mining intensity and depth, the number of rockburst mines in China is increasing rapidly, and the distribution range is also expanding significantly. According to incomplete statistics, there occur several rockburst accidents in China every year, causing a large number of casualties and equipment damage [1-5]. Therefore, how to prevent the rockburst accident is a serious problem faced by China's mining industry. In the past decades, many experts and scholars have done a great deal of research and exploration of the theory, the monitoring and the early warning, prevention, and control technology about rockburst.

In terms of the theory of rockburst, the three-factor theory put forward by Qi et al. [6], the theory of rockburst 
start-up during coal mining by Pan et al. [7], and the instability theory of deformation system by Zhang [8] are very representative. In addition, some other scholars have systematically summarized the mechanism of rockburst according to different production and geology conditions. For example, Zhu et al. [9] studied the mechanism of rockburst caused by fault sliding instability during mining in isolated island working face and summarized the relationship between fault sliding instability and rockburst risk. Shi et al. [10] studied the classification of rockburst from the viewpoint of energy storage and release and analyzed the occurrence mechanism of various types of rockburst. He et al. [11] studied the coupled mechanism of compression and prying-induced rockburst in steeply inclined coal seams and principles for its prevention. Jiang et al. [12] studied the influence of fault parameters on rockburst. Zhang and Jiang [13] proposed the stress criterion and energy criterion for rockburst occurrence, according to different positions of roadways in the coal seam.

For the monitoring and early warning of rockburst, the online monitoring system of mining stress, the microseismic and underground sound monitoring systems are widely used [14-18]. These systems effectively reduce the rockburst accidents. In addition, many scholars have studied the prediction method of rockburst. For example, Cai et al. [19] put up a new coal burst forecasting method in underground coal mines based on the seismic strain energy. Wen et al. [20] studied the rockburst hazard evaluation method. Zhu et al. [21], under the analysis of load transfer mechanisms of key stratum and extremely thick alluvium stratum (ETAS), proposed a theoretical computational model of abutment pressure for ETAS longwall panels. And then, the model was applied to the determination of the abutment pressure distribution in the working face.

In terms of the prevention and control of rockburst, the methods of mining the liberating seam, large-diameter borehole pressure relief of coal seam, water injection of the coal seam, and deep hole blasting of the roof are often used to reduce or eliminate the risk of rockburst [22-26]. For the effect of prevention measures, the drilling cutting method is generally used for verification [27, 28].

Many theories, monitoring and early warning, prevention, and control technology about rockburst, have been achieved, but rockburst accidents still occur from time to time, which shows that there are still many deficiencies in the current understanding and research of rockburst problems. Especially in the deep mining over $1 \mathrm{~km}$, the high ground stress and strong mining stress are very prominent. When the coal seam, the roof, and the floor strata are all in danger of rockburst, how to effectively prevent the dynamic disaster accident is a serious problem. Based on this, taking the deep mining area of Huafeng coal mine in Shandong as the engineering background, this paper studies the above rockburst problems by a lab test, theoretical analysis, and in-situ engineering practice. The research results have some guiding significance for the prevention and control of rockburst in deep mining.

\section{Specimens and Test Procedures}

2.1. Specimen Preparation. The coal and rock samples were from the deep mining area of the Huafeng coal mine in
Shandong, China. These samples were sealed on-site and transported to the laboratory. Each sample was processed into the standard cylindrical specimens with a diameter of $50 \mathrm{~mm}$ and a height of $100 \mathrm{~mm}$; the flatness error of the specimen section does not exceed $0.02 \mathrm{~mm}$, and the axial perpendicularity is less than 0.001 radian, which is suggested by the International Society for Rock Mechanics (ISRM). In addition, the combined specimen is composed of the roof, coal, and floor specimens, and their heights are $30 \mathrm{~mm}, 40 \mathrm{~mm}$, and $30 \mathrm{~mm}$, respectively. Some processed specimens are shown in Figure 1.

2.2. Test Procedures. The tests were conducted using an MTS815.03 servocontrolled rock mechanics test system (MTS Systems Corporation, Eden Prairie, MN, USA) of Shandong University of Science and Technology (see Figure 2). The conventional compression tests were carried out on the coal, roof, floor, and combined specimens. Prior to the test, according to the different types of specimens, a corresponding initial force of $1 \sim 2 \mathrm{kN}$ was applied to the specimen to ensure close contact between the test machine pressure head and the specimen. The displacement control mode was used in the loading process of the specimen, and the displacement loading rate is $0.003 \mathrm{~mm} / \mathrm{s}$. In the conventional triaxial compression test, the confining pressure loading rate of $0.05 \mathrm{MPa} / \mathrm{s}$ was chosen.

\section{Test Results and Analysis}

\subsection{Stress-Strain Characteristics and Constitutive Relation}

3.1.1. Stress-Strain Curve. Figure 3 shows the stress-strain curves of the roof, floor, and coal specimens under different confining pressures. From Figure 3, the prepeak stress-strain curves of deep coal and rock specimens are not smooth, and there are many stress jumping points. Showing that in the deep high ground stress environment, there are abundant microcracks in coal and rock masses, and with the prominent heterogeneity in them. In addition, under the conventional compression loading, the deformation and failure of coal, rock specimens show obvious phased characteristics; that is, their whole stress-strain curve can be roughly divided into prepeak and postpeak parts according to the strength changing trend. The prepeak stress-strain curve can be roughly divided into three phases, namely: the microcrack compaction, elastic deformation, and elastic-plastic deformation phases. In the microcrack compaction phase, with the increase of stress, $\mathrm{d} \sigma / \mathrm{d} \varepsilon$ increases gradually, indicating that the microcracks in the specimen are gradually compacted. In the whole elastic deformation phase, $\mathrm{d} \sigma / \mathrm{d} \varepsilon$ is constant, and the specimen shows linear deformation. After falling into the elastic-plastic deformation phase, with the increase of stress, $\mathrm{d} \sigma / \mathrm{d} \varepsilon$ gradually decreases, and the nonlinear deformation characteristics become gradually obvious. Showing that the microfracture events in the specimen gradually develop from a disordered state to a concentrated state, and the number of failure elements also increases. When the axial stress exceeds the peak strength of the specimen, the specimen falls into the postpeak phase. However, the failure characteristics of different types of 


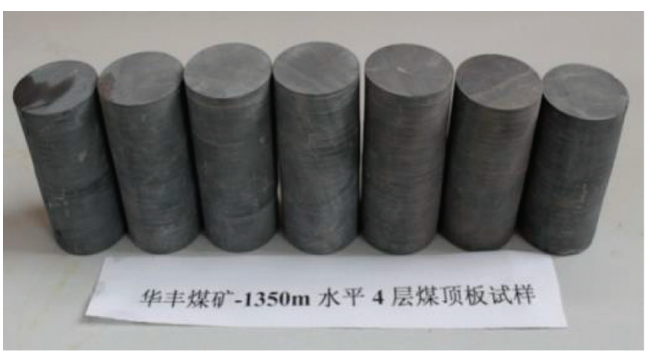

(a)

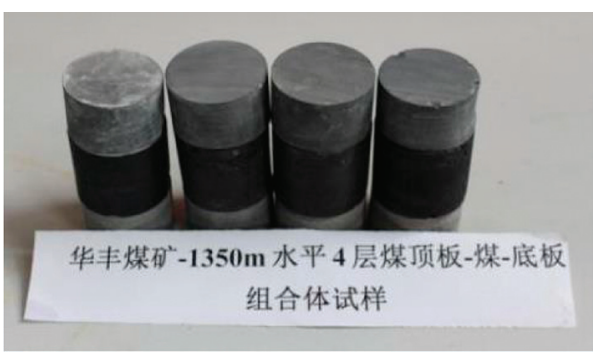

(b)

Figure 1: Some specimens. (a) Rock specimen. (b) Rock-coal-rock combined specimen.

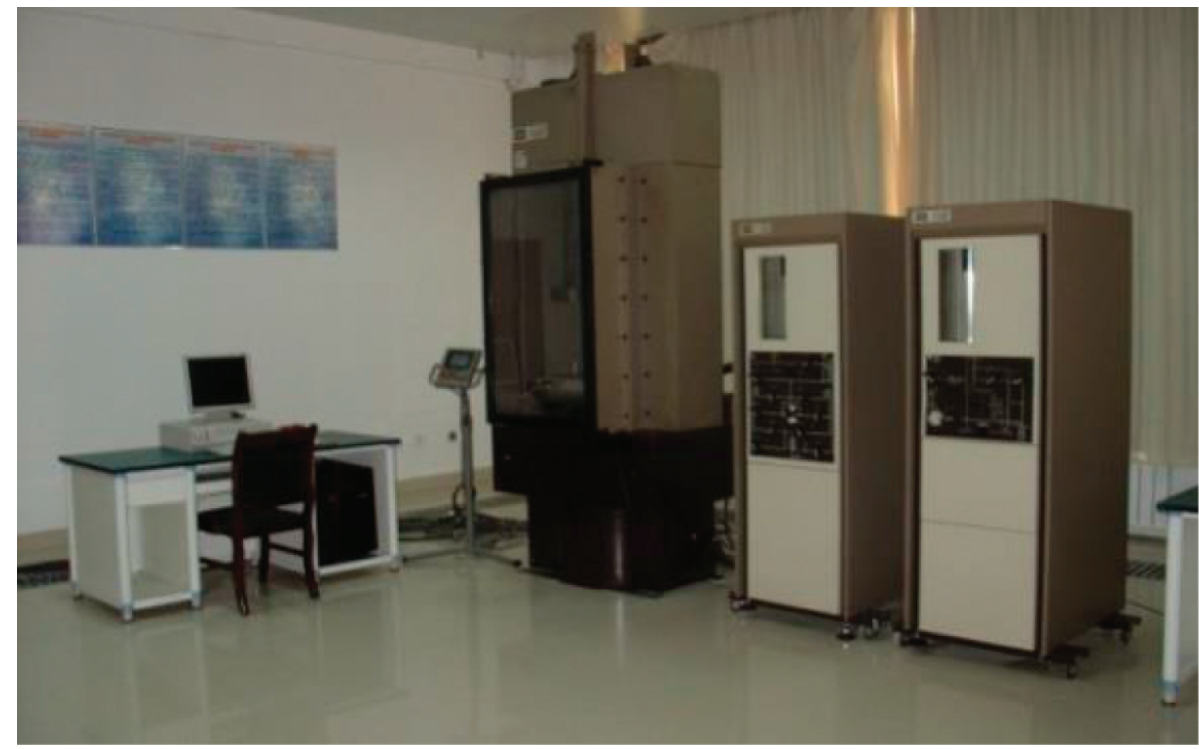

FIGURE 2: MTS815.03 rock mechanics test system.

specimens are diverse under varying confining pressures. Under uniaxial stress state, the failure of roof and floor specimens is brittle, and the coal specimen is progressive. But, under the confining pressures of 3 and $5 \mathrm{MPa}$, the failure of the three specimens is slowly progressive.

3.1.2. Constitutive Relation. The dynamic failure of coal and rock masses is the basic problem in deep mining. In the research, the dynamic failure process of coal and rock masses should be focused on, especially the dynamic evolution process of crack initiation, propagation, and penetration. Therefore, it is necessary to establish the elastic-plastic constitutive relation and the energy criterion for judging the failure of coal and rock masses.

According to elastic-plastic mechanics, the mechanical model can be simplified as a double line stress-strain relation model (see Figure 4). In the prepeak stress-strain curve, assume the linear relation between stress and strain, and the slope of the curve is called elastic modulus $E_{\mathrm{e}}$. In the postpeak stress-strain curve, also assuming the linear relation between stress and strain, the absolute value of the slope of the curve is called descending modulus $E_{\mathrm{d}}$. The $E_{\mathrm{e}} / E_{\mathrm{d}}$ values indicate different bursting liability indexes:

$$
\begin{aligned}
& \text { In pre - peak phase, } \sigma=E_{\mathrm{e}} \varepsilon, \quad \varepsilon<\varepsilon_{\mathrm{c}}, \\
& \text { Inpost - peak phase, } \sigma=\sigma_{\mathrm{c}}-E_{\mathrm{d}}\left(\varepsilon-\varepsilon_{\mathrm{c}}\right), \quad \varepsilon \geq \varepsilon_{\mathrm{c}} \text {, }
\end{aligned}
$$

where $E_{\mathrm{e}}$ is the linear elastic modulus in the prepeak curves, and $E_{\mathrm{d}}$ is the linear descending modulus in the postpeak curves.

The comparison of the prepeak linear elastic modulus $E_{\mathrm{e}}$ and postpeak linear descending modulus $E_{\mathrm{d}}$ of the roof, the floor, and the coal specimens under different confining pressures is shown in Table 1. Under the confining pressure of 0,3 , and $5 \mathrm{MPa}$, the elastic modulus $E_{\mathrm{e}}$ and descending modulus $E_{\mathrm{d}}$ of the roof and floor specimens are significantly higher than that of coal specimen, indicating that the high strength roof and floor will represent a more violent failure process than coal. However, the $E_{\mathrm{e}} / E_{\mathrm{d}}$ of roof and floor specimens is obviously smaller than that of coal. So, the $E_{\mathrm{e}} /$ $E_{\mathrm{d}}$ can be used as an index to evaluate the rockburst strength of coal and rock masses. That is, the smaller the $E_{\mathrm{e}} / E_{\mathrm{d}}$, the greater the rockburst strength. In addition, for the same type of rock, with the increase of confining pressure, the $E_{\mathrm{e}} / E_{\mathrm{d}}$ increases, that is, the rockburst strength decreases. This conclusion shows that the greater the support strength provided to the surrounding rock surface of the roadway, the smaller the failure degree of rockburst. 


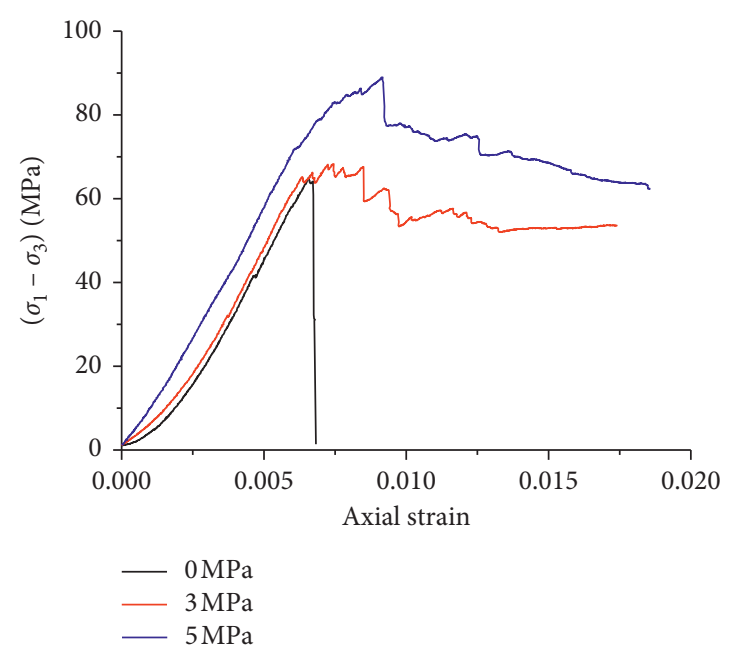

(a)

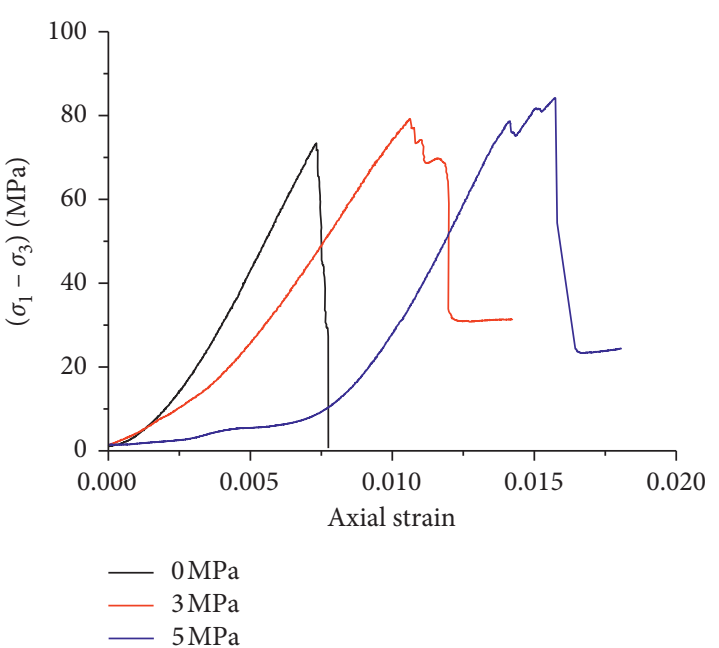

(b)

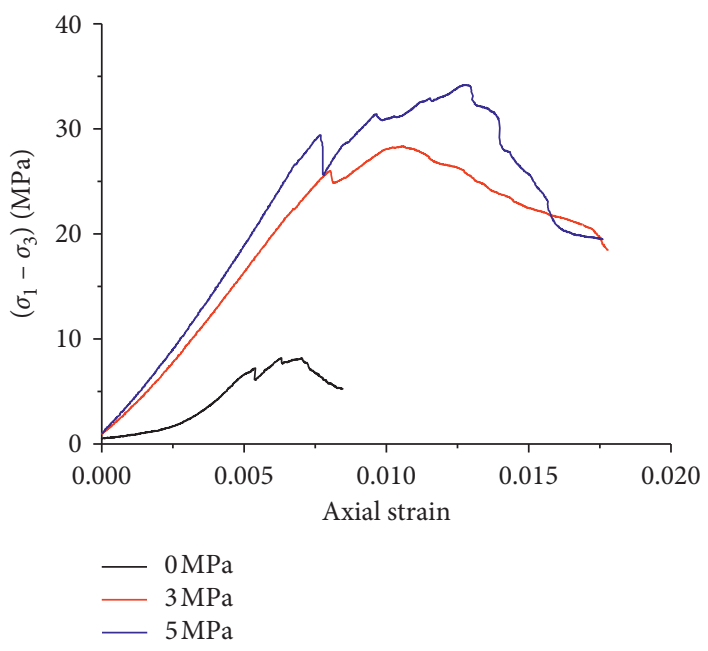

(c)

FIGURE 3: Stress-strain curves of the roof, the floor, and the coal specimens under different confining pressures. (a) Roof specimen. (b) Floor specimen. (c) Coal specimen.

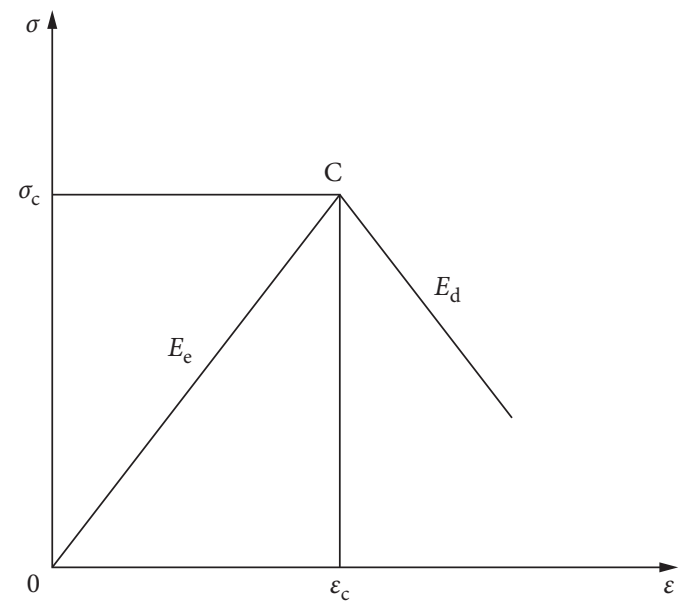

FIGURE 4: Constitutive relation of coal and rock. 
TABle 1: Prepeak linear elastic modulus $E_{\mathrm{e}}$ and postpeak linear descending modulus $E_{\mathrm{d}}$ of the roof, the floor, and the coal specimens under different confining pressures.

\begin{tabular}{lcccc}
\hline $\begin{array}{l}\text { Specimen } \\
\text { type }\end{array}$ & $\begin{array}{c}\text { Confining pressure } \\
(\mathrm{MPa})\end{array}$ & $E_{\mathrm{e}}(\mathrm{MPa})$ & $E_{\mathrm{d}}(\mathrm{MPa})$ & $E_{\mathrm{e}} / E_{\mathrm{d}}$ \\
\hline \multirow{3}{*}{ Roof } & 0 & 12715.23 & 268269.85 & 0.0474 \\
& 3 & 13019.27 & 146717.21 & 0.0887 \\
& 5 & 12982.68 & 90953.37 & 0.1427 \\
\hline \multirow{3}{*}{ Floor } & 0 & 13425.16 & 172543.63 & 0.0778 \\
& 3 & 10280.57 & 71496.94 & 0.1438 \\
& 5 & 13379.67 & 85424.08 & 0.1566 \\
Coal & 0 & 2607.64 & 2028.54 & 1.2855 \\
& 3 & 3551.07 & 2144.20 & 1.6561 \\
& 5 & 4428.88 & 2568.31 & 1.7244 \\
\hline
\end{tabular}

\subsection{Energy Evolution of Loaded Specimen Failure}

3.2.1. Energy Calculation Principle. From the viewpoint of the energy, the rock deformation and failure is a process of energy input, accumulation, dissipation, and release [29]. When the rock element is deformed by compression loading, assuming that all the work done by the external force is absorbed by the rock, the energy " $U$ " input to the rock can be expressed as follows [30]:

$$
U=U_{\mathrm{e}}+U_{\mathrm{d}}
$$

where $U_{\mathrm{e}}$ is elastic strain energy and $U_{\mathrm{d}}$ is dissipated energy.

The elastic strain energy " $U_{\mathrm{e}}$ " is expressed as follows [31]:

$$
U_{\mathrm{e}}=\frac{1}{2 E_{\mathrm{u}}}\left[\sigma_{1}^{2}+2 \sigma_{3}^{2}-2 \mu_{\mathrm{u}}\left(2 \sigma_{1} \sigma_{3}+\sigma_{3}^{2}\right)\right],
$$

where $E_{\mathrm{u}}$ is the elastic modulus and $\mu_{\mathrm{u}}$ is Poisson's ratio.

In the conventional triaxial compression test, the energy " $U$ " is expressed as follows [32]:

$$
U=U_{\mathrm{e}}+U_{\mathrm{d}}=U_{0}+U_{1}+U_{3},
$$

where $U_{0}$ is the energy absorbed in the hydrostatic pressure phase; $U_{1}$ is the energy absorbed in the specimen under the axial force; $U_{3}$ is the consumed energy under the confining pressure (a negative value). When both $U_{0}$ and $U_{3}$ are 0 , it is the energy absorbed in the specimen under uniaxial compression.

The absorbed energy by the specimen " $U_{0}$ " during the hydrostatic pressure phase is expressed as follows [32]:

$$
U_{0}=\frac{3}{2} \frac{1-2 \mu}{E} \sigma_{3}^{2} \text {. }
$$

The energy " $U_{1}$ " and " $U_{3}$ " can be calculated by the integral accumulation method according to the stress-strain curve in the lab test. Figure 5 shows the calculation principle of the energy " $U_{1}$." The calculation equations of energy " $U_{1}$ " and " $U_{3}$ " are as follows:

$$
\begin{aligned}
& U_{1}=\int \sigma_{1} \mathrm{~d} \varepsilon_{1}=\frac{1}{2} \sum_{i=1}^{n}\left(\sigma_{1, i}+\sigma_{1, i+1}\right) \cdot\left(\varepsilon_{1, i+1}-\varepsilon_{1, i}\right), \\
& U_{3}=2 \int \sigma_{3} \mathrm{~d} \varepsilon_{3}=\sum_{i=1}^{n}\left(\sigma_{3, i}+\sigma_{3, i+1}\right) \cdot\left(\varepsilon_{3, i+1}-\varepsilon_{3, i}\right),
\end{aligned}
$$

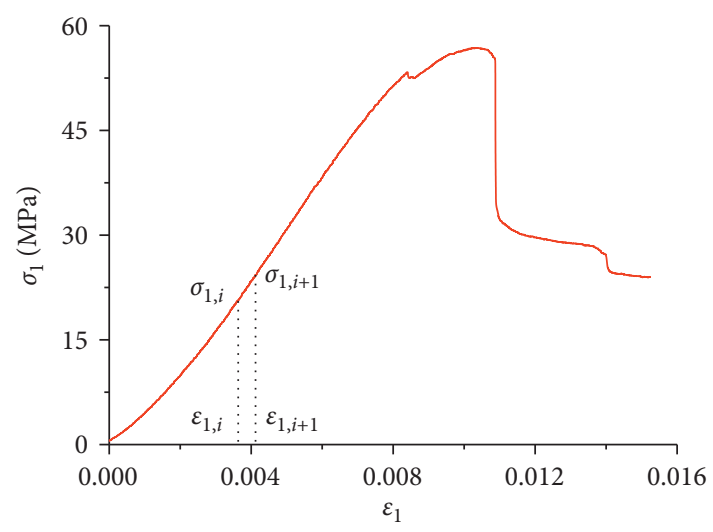

Figure 5: The calculation of the energy $U_{1}$.

where $\sigma_{1, i}$ is the axial stress at the $i$ th sampling point on the axial stress-strain curve, MPa; $\sigma_{1, i+1}$ is the axial stress at the $(i+1)$-th sampling point on the axial stress-strain curve, MPa; $\varepsilon_{1, i}$ is the axial strain corresponding to the sampling point $\sigma_{1, i} ; \varepsilon_{1, i+1}$ is the axial strain corresponding to the sampling point $\sigma_{1, i+1} ; \sigma_{3, i}$ is the confining pressure corresponding to the sampling point $\sigma_{1, i}$; $\sigma_{3, i+1}$ is the confining pressure corresponding to the sampling point $\sigma_{1, \mathrm{i}+1} ; \varepsilon_{3, \mathrm{i}}$ is the circumferential strain corresponding to the sampling point $\sigma_{1, i} ; \varepsilon_{3, i+1}$ is the circumferential strain corresponding to the sampling point $\sigma_{1, i+1}$

Under the uniaxial stress state, the energy equations are simplified as follows:

$$
\begin{aligned}
U & =\int \sigma_{1} \mathrm{~d} \varepsilon_{1}=\sum_{i=0}^{n} \frac{1}{2}\left(\sigma_{1 i}+\sigma_{1 i+1}\right)\left(\varepsilon_{1 i+1}-\varepsilon_{1 i}\right), \\
U_{\mathrm{e}} & =\frac{1}{2} \sigma_{1} \varepsilon_{1}^{\mathrm{e}}=\frac{\sigma_{1}^{2}}{2 E_{\mathrm{u}}} \approx \frac{\sigma_{1}^{2}}{2 E_{0}}, \\
U_{\mathrm{d}} & =\int \sigma_{1} \mathrm{~d} \varepsilon_{1}-\frac{\sigma_{1}^{2}}{2 E_{0}},
\end{aligned}
$$

where $\sigma_{1 i}$ is the axial stress of the $i$ th sampling point on the stress-strain curve, $\mathrm{MPa} ; \sigma_{1 i+1}$ is the axial stress of the $(i+1)$ th sampling point on the stress-strain curve, $\mathrm{MPa} ; \varepsilon_{1 i}$ is the axial strain of the $i$ th sampling point on the stress-strain curve; $\varepsilon_{1 i+1}$ is the axial strain of the $(i+1)$-th sampling point on the stress-strain curve. " $E_{\mathrm{u}}$ " is the unloading elastic modulus, but, so far, there is no consensus on the value of " $E_{\mathrm{u}}$." In order to facilitate the calculation, the elastic modulus " $E_{0}$ " at the late elastic phase is chosen instead of $E_{\mathrm{u}}$ [30].

\subsubsection{Energy Evolution Characteristics}

(1) Influence of Confining Pressure on Energy Evolution of Specimen. Taking the coal specimen as an example, the influence of confining pressure on the specimen energy evolution is illustrated. Under the confining pressure of 0,3 , and $5 \mathrm{MPa}$, the energy evolution curves are shown in Figure 6.

From Figure 6, under the confining pressure of 0,3 , and $5 \mathrm{MPa}$, the evolution trend of input energy, elastic energy, and dissipated energy are the same, but there is an obvious difference at the increasing and releasing rates of energy. Especially, in the postpeak phase, compared with the uniaxial stress state, the 


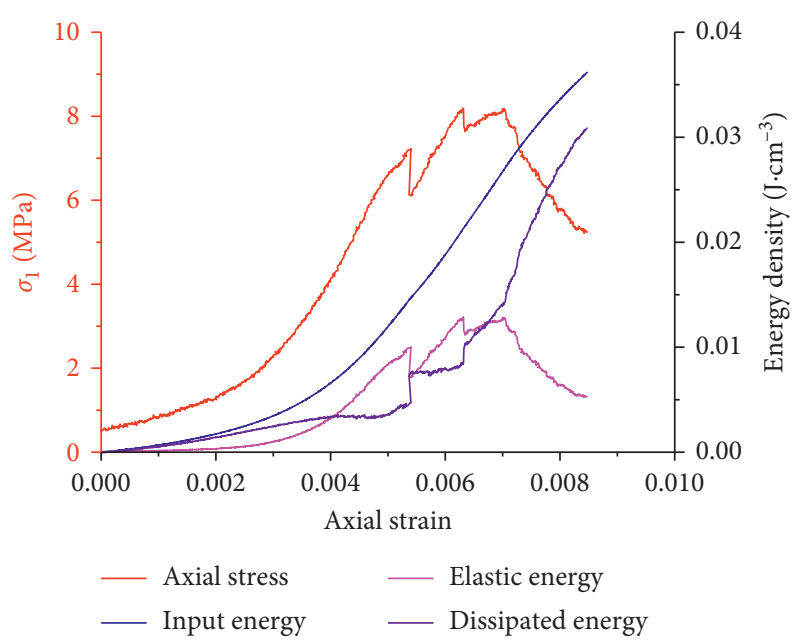

(a)

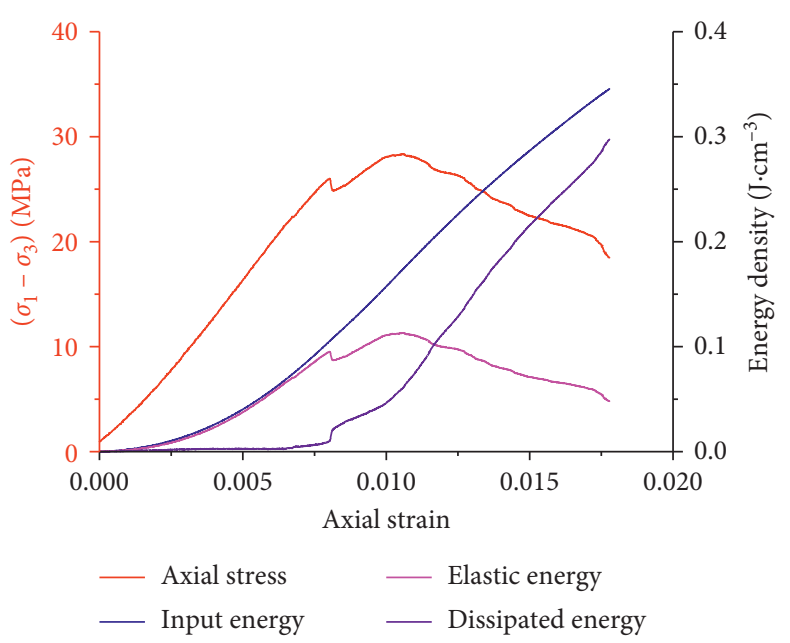

(b)

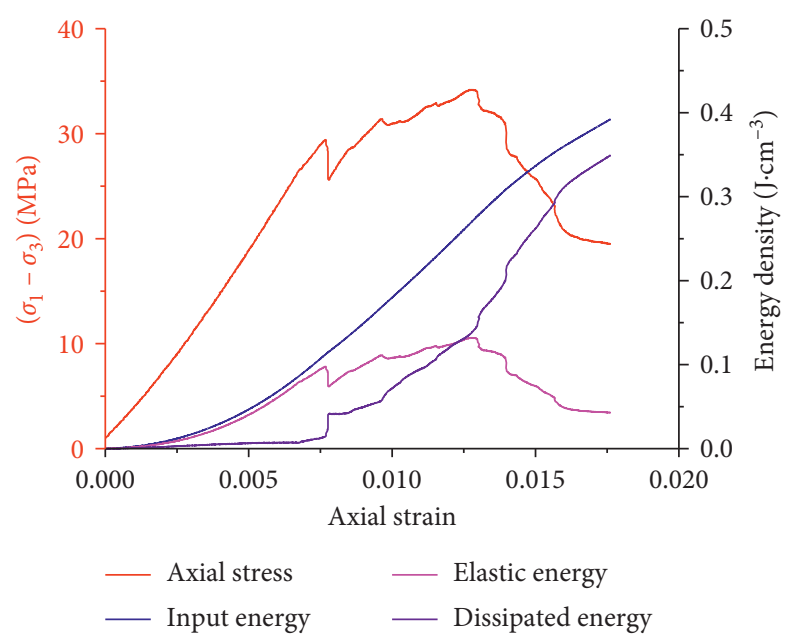

(c)

FIGURE 6: Energy evolution curves of coal specimens in a conventional compression test. (a) $0 \mathrm{MPa}$. (b) $3 \mathrm{MPa}$. (c) $5 \mathrm{MPa}$.

elastic energy decreases slowly, and the dissipated energy increases slowly under the confining pressures of 3 and $5 \mathrm{MPa}$, which shows that the confining pressure can effectively limit the energy dissipation and release after the coal specimen failure. So, in the in-situ engineering, providing enough support strength for the roadway surrounding rock surface can effectively slow down the energy release rate and reduce the rockburst strength.

(2) Energy Evolution Characteristics of Different Types of Specimens under Uniaxial Stress State. Because the most rockburst accidents occur in the coal pillar or roadway with a free surface, this paper focuses on the energy evolution characteristics of roof, floor, coal, and combined specimens under the uniaxial compression.

Figure 7 shows the energy evolution curves of the four types of specimens. The energy evolution of roof and floor specimens is different from that of coal and combined specimens. As for the high strength roof and floor specimens, the input energy, elastic energy, and dissipated energy are very low in the compaction phase. In the prepeak phase, the input energy and the elastic energy increase significantly, but the dissipated energy basically remains the same. After the peak strength is reached, the elastic energy is violently released and the dissipated energy increased dramatically. As to the low strength coal and combined specimens, the energy evolution process is complex. In the early compaction phase, the input energy, elastic energy, and dissipated energy are very low, but in the late compaction phase, the input energy and dissipated energy increase significantly, while the elastic energy only increases slightly. In the elastic phase, the input energy and the elastic energy increase rapidly, while the dissipated energy basically remains the same. In the elastic-plastic phase, the input energy continues to increase because there are many microcracks in the coal. Several local fractures takes place and result in a significant increase of the dissipated energy, while the elastic energy increases in the fluctuation.

3.2.3. Characteristics of the Bursting Energy Index. Under uniaxial compression loading, the prepeak energy, postpeak energy, and bursting energy index of four types of specimens are shown in Table 2. The bursting energy index is the ratio of prepeak energy to postpeak energy. 


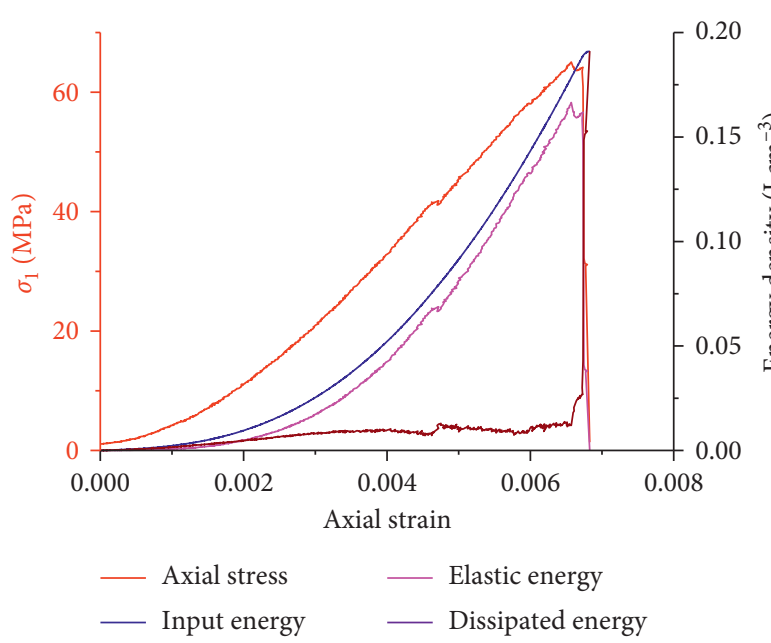

(a)

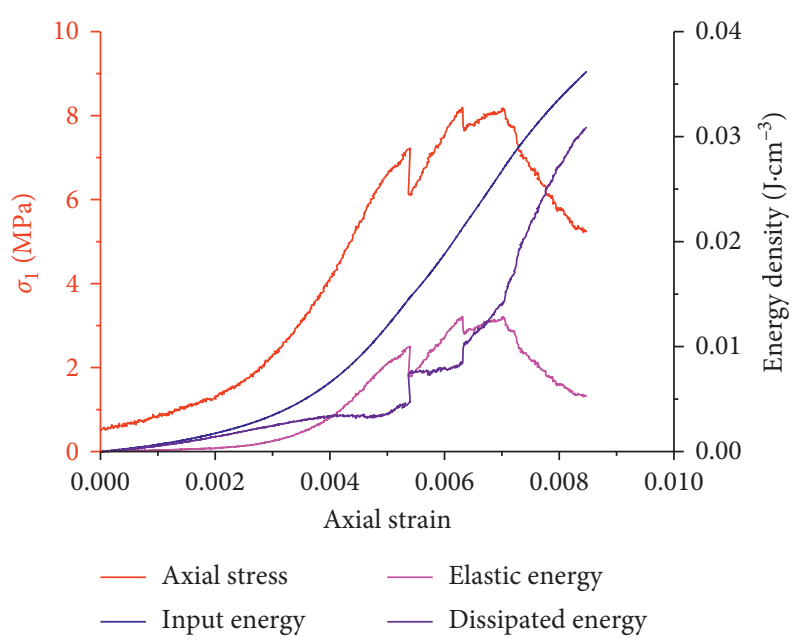

(c)

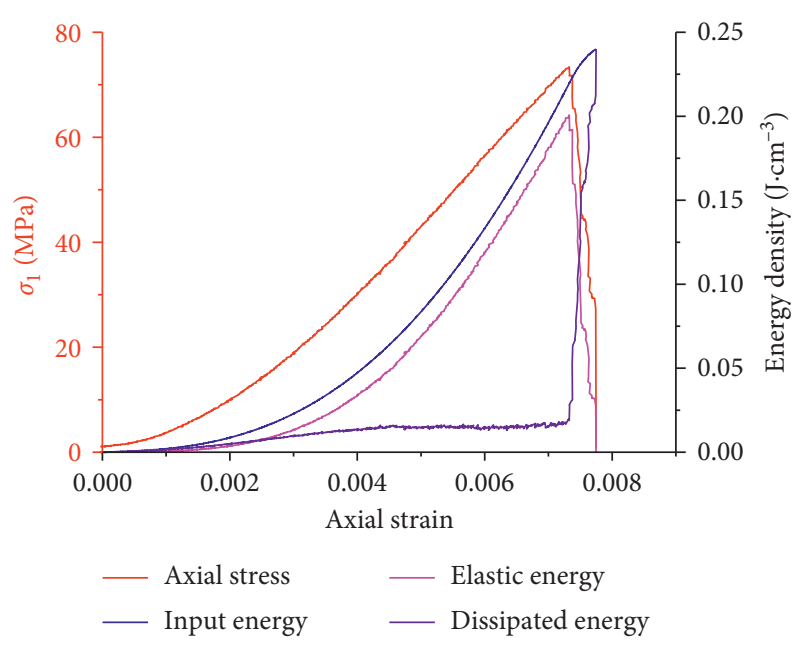

(b)

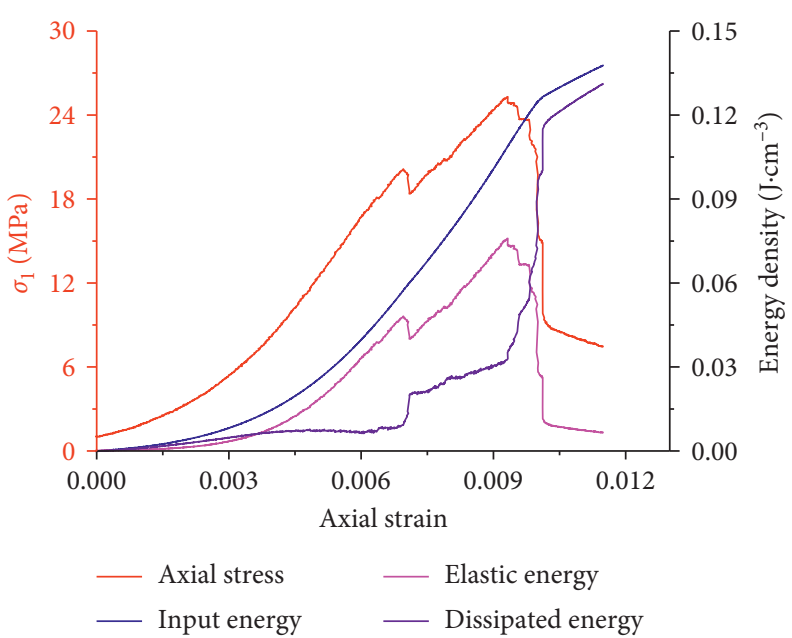

(d)

FigURE 7: Energy evolution curves of various specimens subjected to uniaxial compression loading. (a) Roof specimen. (b) Floor specimen. (c) Coal specimen. (d) Combined specimen.

TABLE 2: Prepeak energy, postpeak energy, and their ratio under a uniaxial state.

\begin{tabular}{lccc}
\hline Specimen type & Prepeak energy $\left(\mathrm{J} \cdot \mathrm{cm}^{-3}\right)$ & Postpeak energy $\left(\mathrm{J} \cdot \mathrm{cm}^{-3}\right)$ & Bursting energy index \\
\hline Roof & 0.1785 & 0.0127 & 14.0551 \\
Floor & 0.2197 & 0.0203 & 10.8227 \\
Coal & 0.0269 & 0.0092 & 2.9239 \\
Combination & 0.1089 & 0.0290 & 3.7552 \\
\hline
\end{tabular}

From Figure 7 and Table 2, in the four types of specimens, the strength of roof and floor specimens is highest, the prepeak input energy and elastic energy are the largest, but the postpeak energy release rate is the fastest and the bursting energy index is the largest, showing that the rockburst destruction force of brittle rock is greater than that of coal. Therefore, in the in-situ engineering, the prevention and control of the roof and floor rockburst should be highly valued, because once the rockburst occurs, the destructive force is much greater than that of the coal seam. For the roof and floor to easy accumulate energy, the water injection softening and blasting can be used to increase their internal cracks and reduce the strength so that the failure mode is changed from brittleness to ductility and finally reduce the accumulated energy in the strata and slow down the energy release rate. Compared with the coal specimen, the bursting energy index of the combined specimen is slightly larger, which indicates that the rockburst destruction force of the thin or medium-thick coal seam clamped by the rock strata is greater than that of the single thick coal seam. The main reason is that the elastic energy accumulated in the roof and floor is released rapidly and converted into the kinetic 
energy of the coal mass movement when the coal seam is collapsed by the rockburst.

\subsection{Discussion}

(1) From Figure 7, the released energy of the specimen at the peak strength is not necessarily the largest. The maximum released energy usually occurs at some point on the postpeak stress-strain curve. Because a large amount of crack penetration needs to take some time to develop after peak strength. This well explains the reason that the rockburst does not occur immediately when the stress concentration exceeds the peak strength of coal and rock masses in the stope. So, it is the key to prevention and control of dynamic disasters to study the postpeak stress-strain curve of coal and rock. According to the stress-strain curves of coal and rock specimens, when the brittle failure is more serious, the larger the $E_{\mathrm{d}}$, the smaller the $E_{\mathrm{e}} / E_{\mathrm{d}}$, and the more likely the rockburst occur. On the contrary, when progressive ductile failure is more obvious, the smaller the $E_{\mathrm{d}}$, the larger the $E_{\mathrm{e}} / E_{\mathrm{d}}$, and the possibility of rockburst is reduced.

(2) The dissipation and release of energy are the essential properties during the damage and failure process of loaded coal and rock. So, the dissipated energy " $U_{\mathrm{d}}$ " at peak strength can be used as an energy indicator to predict the occurrence of rockburst disasters. $U_{\mathrm{d}}=\sigma_{c}^{2} / 2 E_{\mathrm{c}} ; \sigma_{\mathrm{c}}$ is the peak strength, $E_{\mathrm{s}}$ is the elastic modulus. In the in-situ engineering, rockburst will occur when the deformation energy stored in the whole coal and rock mass exceeds the index " $U_{\mathrm{d}}$."

(3) The test results show that the increase of confining pressure can effectively limit the energy dissipation and release after coal specimen failure. So, in the insitu engineering, it is an important measure to improve the surface restraint and support strength of coal roadway for reducing the occurrence intensity and probability of rockburst.

(4) According to the above findings, when mining the deep rockburst coal seam, both the regional and local control measures should be adopted. As for the regional control of rockburst, liberating seam mining can be the most important method. After the mining of the liberating seam, the cracks in the roof and floor strata of the protected coal seam increase and reduce their stress concentration and the bending energy index. As for the local control of rockburst, the large-diameter borehole pressure relief, water injection cracking, and blasting can be carried out in advance of the working face. After the implementation of local control measure, the internal cracks of coal and rock masses increase, the stress concentration of working face reduces, and the energy dissipation increases, and finally, the probability and intensity of rockburst will be significantly reduced or eliminated.

\section{Engineering Practice of Rockburst Prevention and Control in Deep Mine}

4.1. Engineering Background. Huafeng coal mine is located in Taian city, Shandong, China, and is a serious rockburst mine. The main mining seams are No. 1, No. 4, and No. 6 coal seams. Among them, the bursting liability of No. 4 coal seam is the strongest. So, this paper takes No. 1412 fully mechanized caving face with strong rockburst in No. 4 coal seam as an example to study the prevention and control technology of rockburst. No. 1412 working face is located in the middle east of the well field. The right side of No. 1412 working face is the goaf of No. 1411 working face, and the left is the solid coal mass; the east is the natural boundary of No. 4 coal seam; the west is the No. 5 exploration line. The layout of No. 1412 working face is shown in Figure 8. The elevation range of the upper and lower roadways of No. 1412 working face is from -1010 to $-1100 \mathrm{~m}$, the ground elevation is $+120 \mathrm{~m}$, and the buried depth is about $1200 \mathrm{~m}$. The strike length is $2200 \mathrm{~m}$, and the inclined length is $157 \mathrm{~m}$. The average dip angle is $30^{\circ}$. The average thickness of No. 4 coal seams is $6.2 \mathrm{~m}$. According to the bursting liability test, the duration of dynamic fracture (DT) of No. 4 coal seam is $289 \mathrm{~ms}$, the bursting energy index $\left(K_{\mathrm{E}}\right)$ is 1.54 , the elastic strain energy index $\left(W_{\mathrm{ET}}\right)$ is 2.43 , and the uniaxial compressive strength $\left(R_{\mathrm{c}}\right)$ is $10.96 \mathrm{MPa}$. The coal seam is with weak bursting liability after synthesis evaluation. Table 3 lists the bursting liability parameters of No. 4 coal seam. The bending energy index of No. 4 coal roof is $77.99 \mathrm{~kJ}$, which is the rock stratum with weak bursting liability. The bending energy index of No. 4 coal floor is $179.94 \mathrm{~kJ}$, which is the rock stratum with strong bursting liability.

After synthesis evaluation, the eight areas of No. 1412 working face are classified as risk zones of rockburst. In order to facilitate the management, the adjacent risk zones are combined, and finally, there are four risk zones. Among them, there are two low-risk zones, one medium risk zone, and one high-risk zone. The upper roadway range affected by the first roof pressure of No. 1412 working face is determined as the low risk zone (see green zone of No. 1412 upper roadway in Figure 8). The range away from the cutting hole from 0 to $157 \mathrm{~m}$ is determined as the medium risk zone (see yellow zone in Figure 8). The lower roadway range away from the cutting hole from 157 to $530 \mathrm{~m}$ is determined as the low risk zone (see green zone of No. 1412 lower roadway in Figure 8). The upper roadway range away from the cutting hole from 157 to $530 \mathrm{~m}$ is determined as the high-risk zone (see red zone of in Figure 8).

\subsection{Rockburst Prevention and Control Technology}

4.2.1. Regional Prevention and Control of Liberating Seam Mining. As mentioned previously, No. 4 coal seam and its roof are with weak bursting liability, and the floor is with strong bursting liability. If directly mining No. 4 coal seam, it is difficult to take effective measures to prevent and control the rockburst accidents. According to the achievements of Section 3, the first measure preventing and controlling 


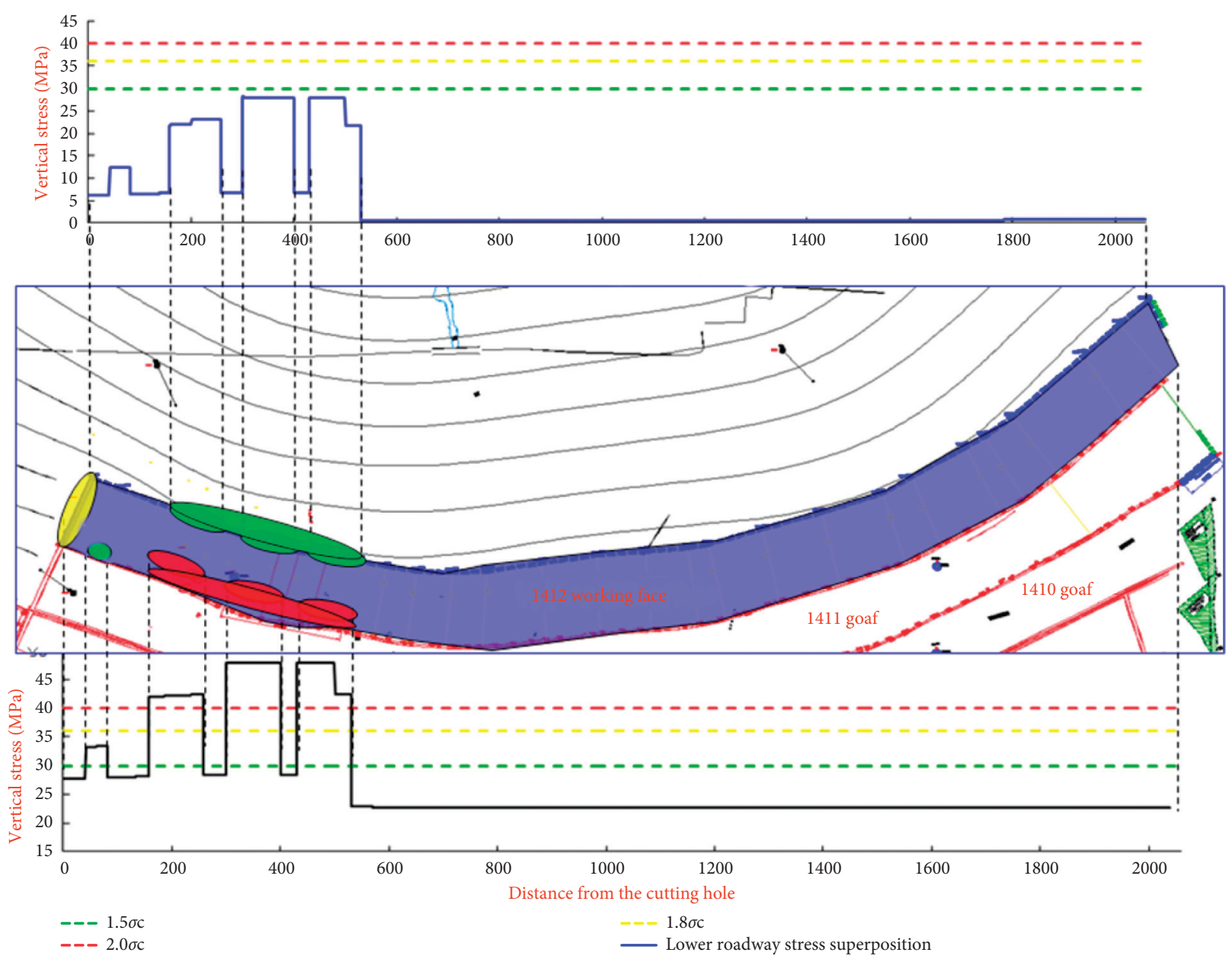

FIgURE 8: Layout of No. 1412 working face.

TABLE 3: The bursting liability parameters of No. 4 coal seam.

\begin{tabular}{lcccc}
\hline Parameters & DT $(\mathrm{ms})$ & $K_{\mathrm{E}}$ & $W_{\mathrm{ET}}$ & $R_{\mathrm{C}}$ \\
\hline Value & 289 & 1.54 & 2.43 & 10.96 \\
\hline
\end{tabular}

rockburst is to carry out the mining of liberating seam. Then, mining in the protected area of No. 4 coal seam can effectively reduce or eliminate the rockburst accidents. According to the geological data of the mine, No. 1 coal seam with weak bursting liability is $1.17 \mathrm{~m}$ thick, $41.87 \mathrm{~m}$ above the No. 4 coal seam. After mining, the cracks in the overlying strata of No. 4 coal seam can be extensively developed, the rock stress concentration can be reduced, and finally, it can reduce the risk of roof rockburst. The No. 6 coal seam with weak bursting liability is $1.3 \mathrm{~m}$ thick, $44.62 \mathrm{~m}$ below the No. 4 coal seam. After mining, the floor pressure is released, and the risk of floor rockburst is reduced. Because No. 1 and No. 6 coal seams are thin, their mining does not destroy the mining conditions of No. 4 coal seam. So, it is very conducive to the safe mining of the protected area in No. 4 coal seam if the two coal seams are firstly mined to form the stress relief condition of a double liberating coal seam mining. After considering the spatial position of the stope and the time effect of the liberating seam, No. 1111 and No. 1112 working faces of No. 1 coal seam, and No. 1612 and No. 1613 working faces of No. 6 coal seam should be firstly mined before the mining of No. 1412 working face so that the No. 1412 working face is in a low-stress area.

4.2.2. Local Prevention and Control of Large-Diameter Borehole Pressure Relief in Advance of Working Face. According to the theories of mine rock mechanics and mine pressure, although in mining pressure relief condition of double liberating seams, the stress concentration still occurs in the key parts of the working face, such as the first roof pressure, the working face square, and the geological structure area. In order to ensure that the working face is always mined under the low-stress state, the local control measure must be carried out, such as the large-diameter pressure relief borehole, water injection cracking, blasting, and so on. Especially, the implementation of a large-diameter pressure relief borehole can effectively reduce the stress concentration of the coal mass, increase the energy dissipation, and finally reduce the probability and strength of rockburst. The pressure relief principle of the large-diameter borehole is shown in Figure 9.

The parameters of deep large-diameter pressure relief borehole in coal seam mainly include the depth, spacing, and diameter of the borehole. The drilling depth should ensure that the coal seam is in a nearly three-dimensional stress 


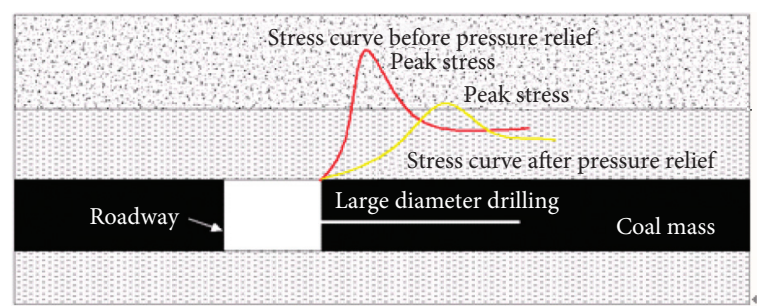

FIGURE 9: Pressure relief principle of the large-diameter borehole.

state after pressure relief, and the coal mass not easy to rush out (the resistance is greater than the rush out force). The borehole spacing should be determined according to the burial depth, hardness, and rockburst risk of the coal seam. Based on the elastic-plastic mechanics analysis of the breaking, plastic, elastic, and original stress zones around the circular borehole and the stress in these zones, and combined with the in-situ practice experience, the diameter of the pressure relief borehole is chosen as $182 \mathrm{~mm}$, and the depth is not less than $20 \mathrm{~m}$.

(1) Prepressure Relief of Large-Diameter Borehole in Advance of Working Face. Before mining, the large-diameter borehole is carried out for the coal mass pressure relief within $300 \mathrm{~m}$ in advance of the upper and lower roadways of No. 1412 working face. The drilling equipment is the CMS1-6000/55 hydraulic drill, as shown in Figure 10.

Within the range of $300 \mathrm{~m}$ in advance of working face, the low risk, medium risk, and high-risk zones, the large-diameter pressure relief borehole with a depth of $30 \mathrm{~m}$ is constructed at the spacing of $5 \mathrm{~m}, 3 \mathrm{~m}$, and $1 \mathrm{~m}$, respectively. Because both sides of No. 1412 lower roadway are the solid coal mass, the large-diameter pressure relief boreholes are arranged on both sides of the roadway. The dip angle of the boreholes is the same as that of the coal seam. According to the distribution characteristics of the abutment pressure in the stope, and after considering the safety factor, the borehole depth is determined to be $20 \mathrm{~m}$. The lower side of No. 1412 upper roadway is the solid coal mass, and the upper side is near the No. 1411 goaf, so the borehole is arranged at the lower side of the roadway. Similarly, according to the distribution characteristics of the abutment pressure in the stope, and after considering the safety factor, the borehole depth is determined to be $30 \mathrm{~m}$. In the in-situ engineering practice, it is necessary to ensure that the pressure relief boreholes are constructed within $300 \mathrm{~m}$ in front of the working face.

For the special zones requiring enhanced pressure relief, after the implementation of the large-diameter borehole, it is necessary to use the drilling cutting method to test the effect of pressure relief. If the amount of coal scraps exceeds the standard or there are dynamic phenomena (such as borehole sticking, roof shaking, coal blasting, etc.) in the process of drilling, the effect of pressure relief is not up to the standard. At this time, after the synthesis evaluation of these risk zones and determination of the risk level, the large-diameter boreholes are constructed again according to the required pressure relief parameters. And then test the effect of pressure relief until up to the standard.
(2) Safety Coordination Control of Reinforcement-Pressure Relief in Rockburst Roadway Surrounding Rock. According to the conclusion of Section 3, the increase of confining pressure can effectively limit the energy dissipation and release after coal specimen failure. So, in the in-situ engineering, it is an important measure to improve the surface restraint and support strength of coal roadway for reducing the occurrence intensity and probability of rockburst.

Through in-situ measurement and engineering practice, the supporting scheme of the roadway surrounding rock is determined. The support parameters of the roof are as follows: the $\Phi 6 \mathrm{~mm}$ metal net with a grid size of $100 \mathrm{~mm} \times 100 \mathrm{~mm}$ is laid on the roof and two sides of the roadway. Then, the one trapezoid-typed steel band with a length of $4 \mathrm{~m}$ and the six $\Phi 22 \mathrm{~mm} \times \mathrm{L} 4300 \mathrm{~mm}$ anchor cables are combined to install in the roadway roof, and each anchor cable installed a $150 \mathrm{~mm} \times 150 \mathrm{~mm} \times 30 \mathrm{~mm}$ load-bearing plate. Each anchor cable is anchored using two MSZ2850 resin anchorage agents with a pretension of $80 \mathrm{kN}$, and the anchorage force is not less than $150 \mathrm{kN}$. Besides, along the roadway strike, the anchor cable beam is installed in the roadway roof and consists of one beam with a length of $4.8 \mathrm{~m}$ and three $\Phi 22 \mathrm{~mm} \times \mathrm{L} 10300 \mathrm{~mm}$ anchor cables with the interval of $1800 \mathrm{~mm}$. Each anchor cable is anchored using three MSM2350 resin anchorage agents with a pretension of $80 \mathrm{kN}$, and the anchorage force is not less than $200 \mathrm{kN}$. The spacing of the anchor cable beam is set to $1.0 \mathrm{~m}$. The support parameters of the solid coal side are as follows: The one trapezoid-typed steel band with a length of 2.2 or $1.3 \mathrm{~m}$ and the five $\Phi 22 \mathrm{~mm} \times \mathrm{L} 2500 \mathrm{~mm}$ metal screw equal-strength bolts are combined to install in the solid coal side of the roadway. The bolts in the top corner of the roadway are inclined to the roadway roof, with an angle of $15^{\circ} \sim 20^{\circ}$ to the horizontal direction. And the bolts in the bottom corner of the roadway are inclined to the roadway floor, with an angle of $10^{\circ} \sim 30^{\circ}$ to the horizontal direction. Besides, the channel steel with a length of $3.2 \mathrm{~m}$ is vertically installed on the two sides of the roadway. There are three anchor cable holes in the channel steel, and the spacing of holes is $1.2 \mathrm{~m}$. The $\Phi 22 \mathrm{~mm} \times \mathrm{L} 10300 \mathrm{~mm}$ anchor cables are installed in the top hole, the $\Phi 22 \mathrm{~mm} \times \mathrm{L} 2500 \mathrm{~mm}$ metal screw equal-strength bolts installed in the middle hole, and the $\Phi 22 \mathrm{~mm} \times \mathrm{L} 6300 \mathrm{~mm}$ anchor cables installed the bottom hole. The spacing of channel steel is set to $1.0 \mathrm{~m}$. The support parameters of the roadway side near goaf are as follows: The anchor cable beam is supported by the shed leg made of the U29 steel. The shed leg is composed of two parts, the upper part is $2.0 \mathrm{~m}$ long, the lower part is $3.2 \mathrm{~m}$ long, and the connecting part of the two is overlapped by $0.5 \mathrm{~m}$. The pretension moment of each bolt is not less than $400 \mathrm{~N} \cdot \mathrm{m}$, and the anchorage force not less than $120 \mathrm{kN}$.

\subsection{Information Monitoring and Early Warning of Rockburst}

4.3.1. Analysis of Microseismic and Geoacoustic Monitoring. Figure 11 shows the microseismic event frequency and energy versus time curves of the No. 1411 working face without advance pressure relief and the No. 1412 working face with advanced pressure relief. The frequency of microseismic events in No. 1411 working face is much, and the 


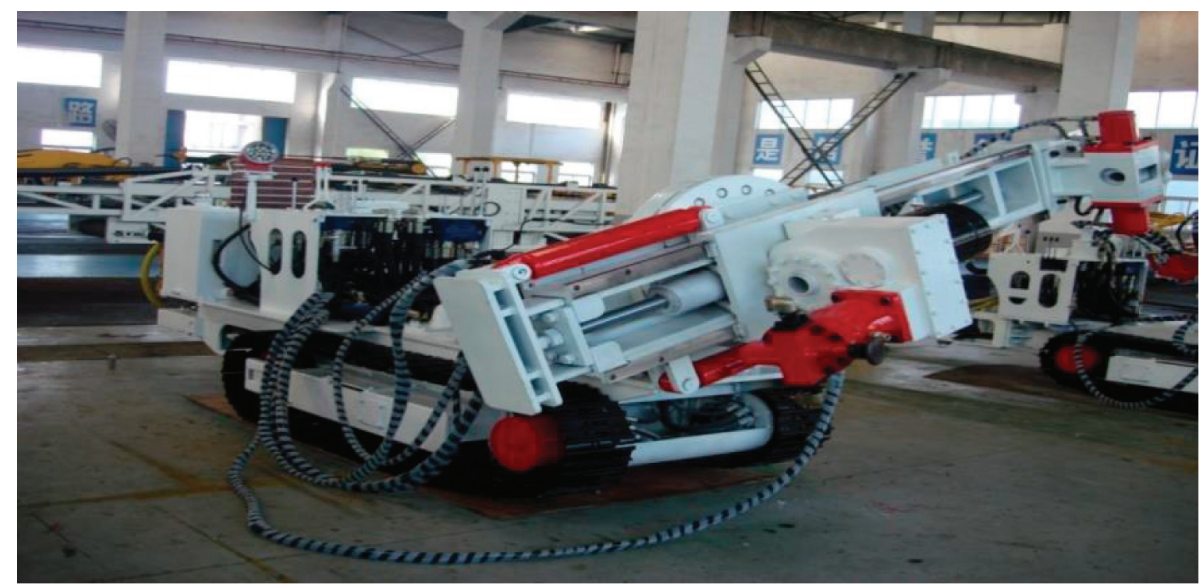

Figure 10: GMS1-6000/55 hydraulic drill for coal mine.

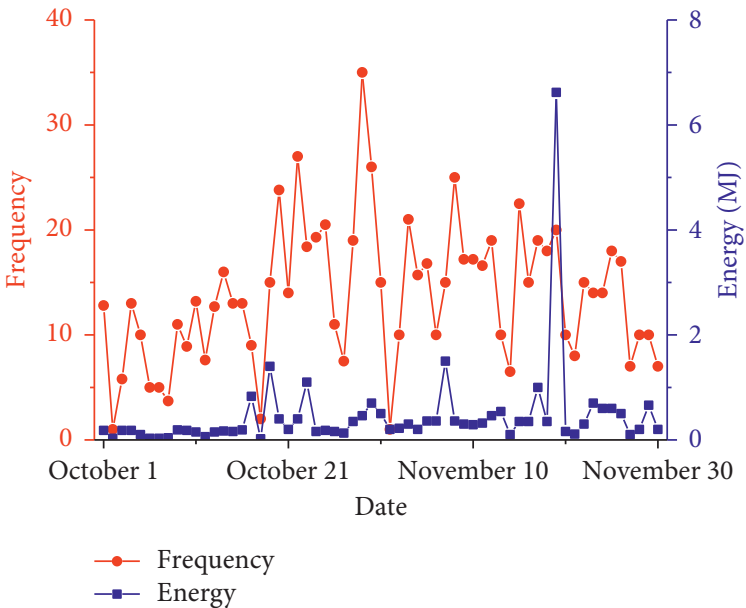

(a)

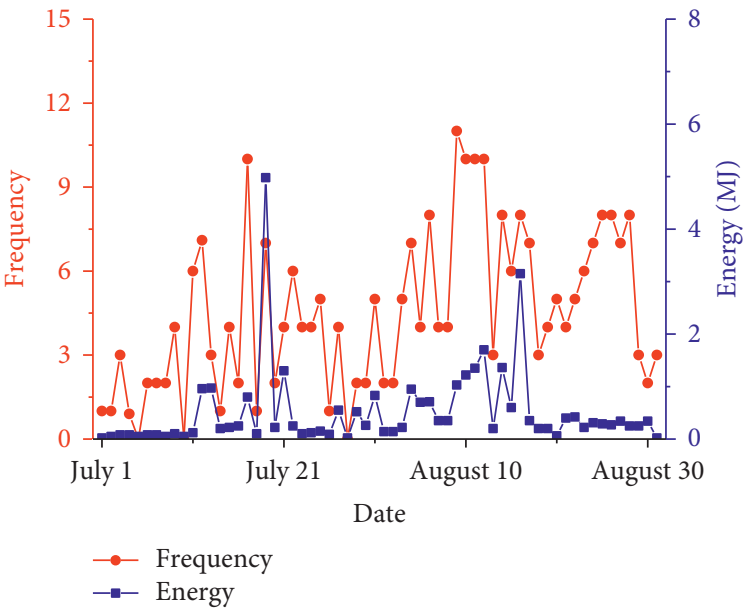

(b)

FIgURE 11: Microseismic monitoring results during mining. (a) No. 1411 working face without advanced pressure relief. (b) No. 1412 working face with advanced pressure relief.

maximum is up to 35 . However, in No. 1412 working face, after implementation of large-diameter pressure relief borehole, the maximum frequency of microseismic events is only 11. Figure 12 shows the energy release and event frequency monitored by the geoacoustic monitoring system during the mining of No. 1412 working face. The event frequency is very high, but the energy very low, indicating that there is a small-sized fracture in coal mass. The smallsized fracture releases the energy accumulated in the coal mass and reduces the stress concentration. Through the data of microseism and geoacoustic monitoring systems, it can be concluded that the large-diameter pressure relief borehole can effectively reduce the bursting risk of the working face.

4.3.2. Real Time Stress Monitoring and Analysis. In order to effectively evaluate the pressure relief effect of the largediameter borehole, in the upper and lower roadways of No.
1412 working face, the borehole stress sensors are arranged to monitor the stress evolution of coal mass in real time. The first measuring station is arranged at a spot of $30 \mathrm{~m}$ from No. 1412 cutting hole, and the subsequent stations are arranged according to the interval of $30 \mathrm{~m}$ in turn. Each station is equipped with two measuring points with the spacing of $2 \mathrm{~m}$, and the installation depth of borehole stress sensors is $14 \mathrm{~m}$ and $18 \mathrm{~m}$, respectively. The early warning of borehole stress is divided into two levels, namely: yellow and red warnings; the former warning value is set as $10 \mathrm{MPa}$, and the latter warning value is $12 \mathrm{MPa}$. With the advance of the working face, timely dismantle the borehole stress sensors and move them forward to arrange to ensure that the monitoring range is not less than $300 \mathrm{~m}$.

Figure 13 shows the monitoring results of the advancing abutment stress in No. 1411 working face with a section coal pillar. The maximum stress and the maximum change rate appear in the right borehole of No. 51 measuring station, the depth of this borehole is $18 \mathrm{~m}$, and $169.8 \mathrm{~m}$ away from the 


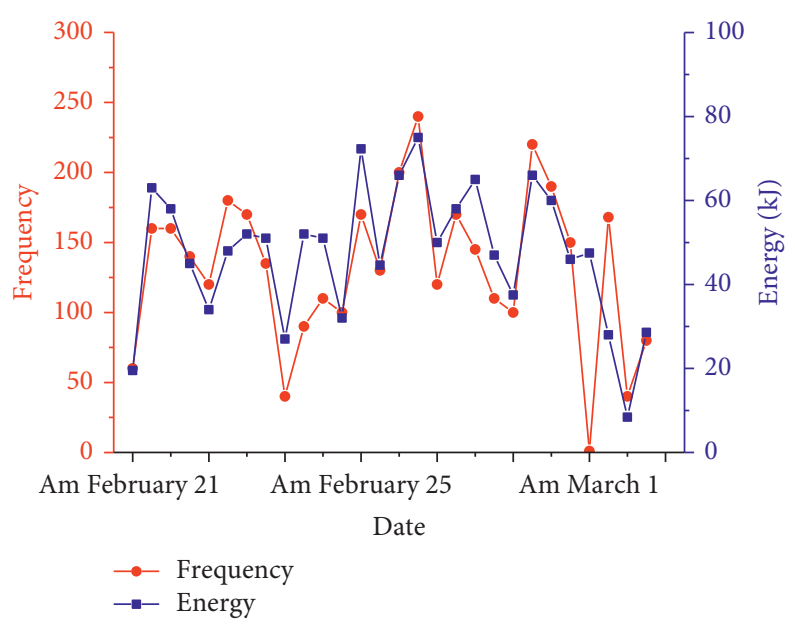

FIGURE 12: Geoacoustic monitoring results during mining.

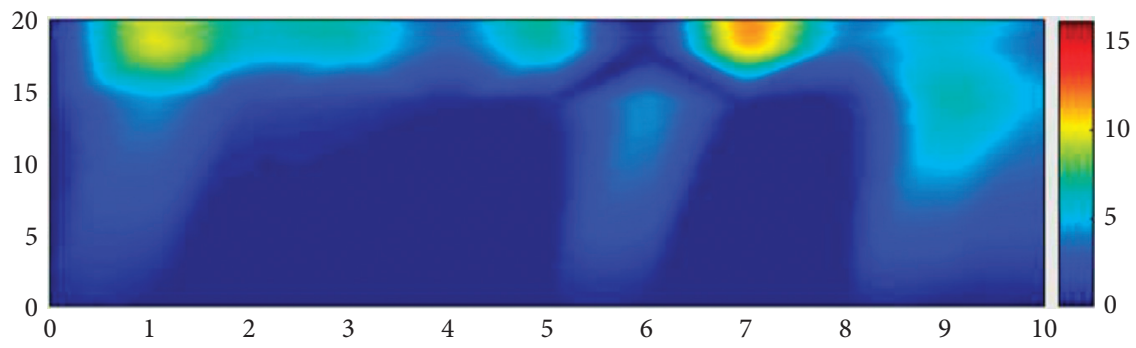

(a)

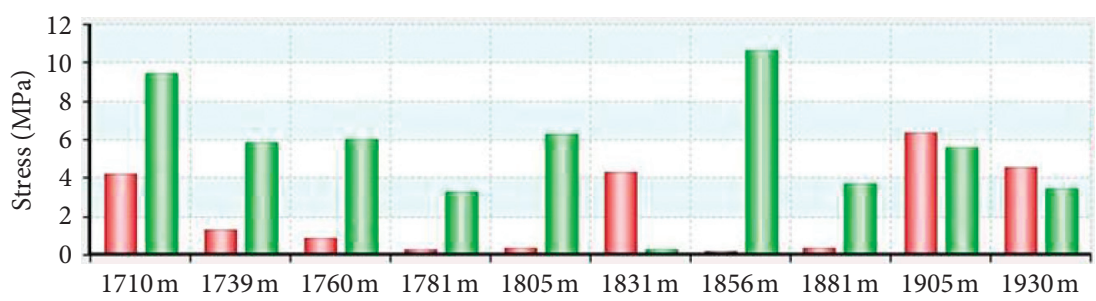

口 Short hole

G Deep hole

(b)

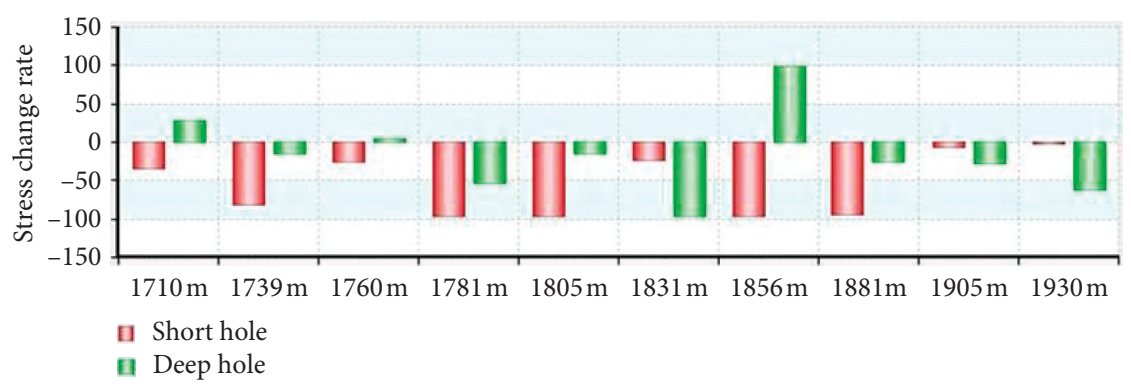

(c)

FIGURE 13: Stress monitoring results of No. 1411 working face without advancing pressure relief. (a) Stress nephogram of No. 1412 upper roadway in Huafeng coal mine. (b) Stress histogram of the typical observation stations. (c) Stress change rate of typical observation stations.

working face. The stress value is $10.65 \mathrm{MPa}$, and the change rate is $99.39 \%$, showing a yellow warning. Stress values of the other boreholes are lower than $10 \mathrm{MPa}$, indicating that there is a good pressure relief effect in coal mass, and the prevention and control measures can effectively eliminate the rockburst accidents. 


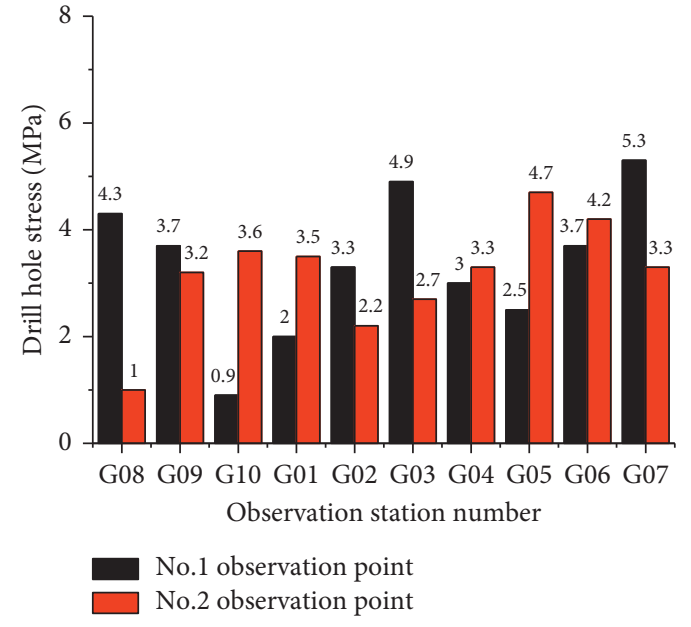

(a)

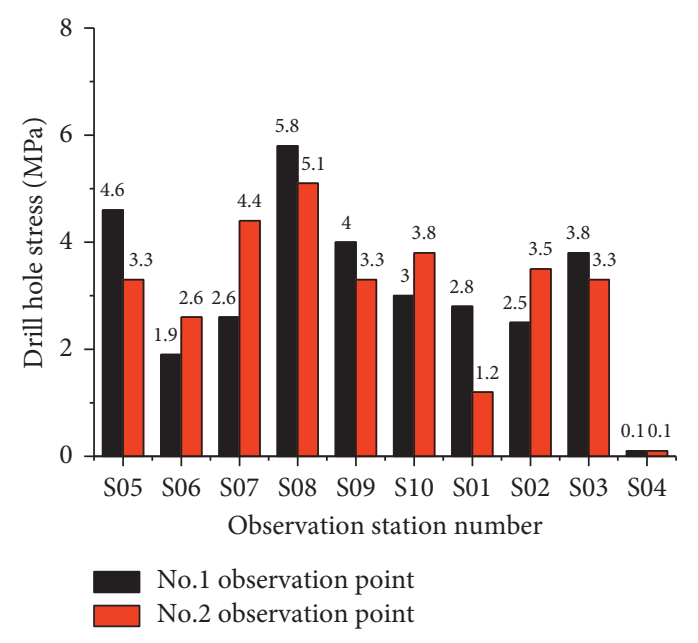

(b)

Figure 14: Stress monitoring results of No. 1412 working face on March 1. (a) No. 1412 upper roadway. (b) No. 1412 lower roadway.

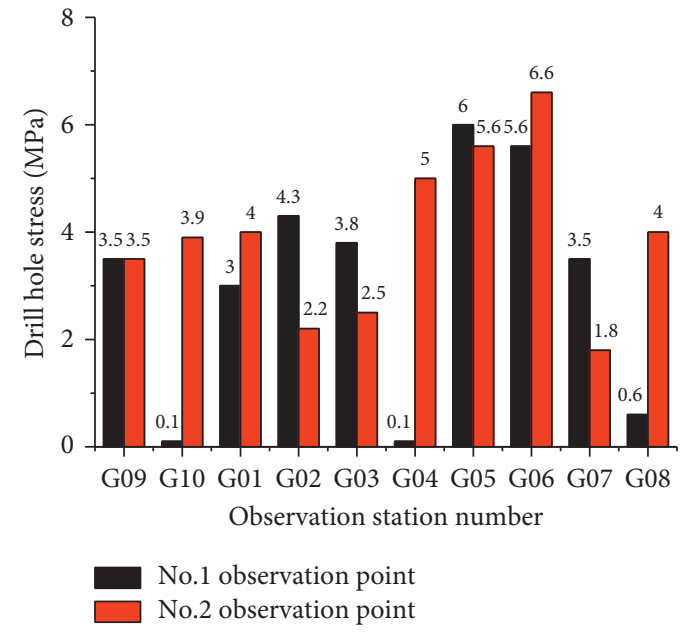

(a)

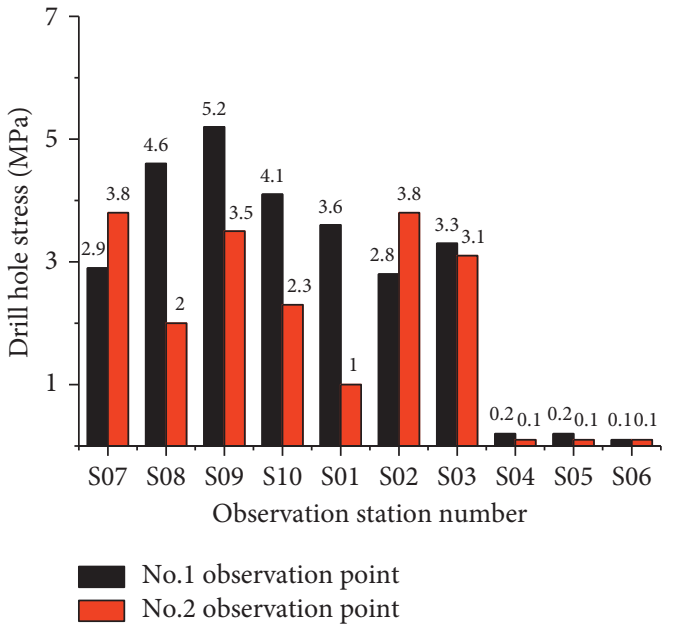

(b)

Figure 15: Stress monitoring results of No. 1412 working face on March 2. (a) No. 1412 upper roadway. (b) No. 1412 lower roadway.

Figures 14 and 15 show the stress monitoring results of No. 1412 working face under the mining conditions of "the mining of liberating seam" + "the implementation of largediameter pressure relief borehole in advance of working face." On March 1, the maximum stress of the short borehole in No. 1412 upper roadway is $5.3 \mathrm{MPa}$, and the maximum stress of the deep borehole is $4.7 \mathrm{MPa}$; the maximum stress of the short borehole in No. 1412 lower roadway is $5.8 \mathrm{MPa}$, and the maximum stress of deep borehole is $5.1 \mathrm{MPa}$. On March 2, the maximum stress of the short borehole in No. 1412 upper roadway is $6.0 \mathrm{MPa}$, and the maximum stress of the deep borehole is $6.6 \mathrm{MPa}$, the maximum stress of the short borehole in No. 1412 lower roadway is $5.2 \mathrm{MPa}$, and the maximum stress of deep borehole is $3.8 \mathrm{MPa}$. The above data show that the stress of No. 1412 working face is lower than that of No. 1411 working face with a section coal pillar, and the stress is less than the yellow warning value. So, after mining the liberating seam, and then the implementation of large-diameter pressure relief borehole in advance of the working face can ensure the low-stress mining in No. 1412 working face. The combined measures of "the mining of liberating seam t the implementation of large-diameter pressure relief borehole in advance of working face" provide the theoretical guidance and engineering reference for the safe mining of rockburst mine.

\section{Conclusions}

Through the lab test and in-situ engineering practice, the main conclusions of this paper are as follows:

(1) The maximum released energy of the specimen usually occurs at some point on the postpeak stress-strain curve. Because a large amount of crack penetration needs to take some time to develop after peak strength. So, it is the key of 
prevention and control of dynamic disasters to study the postpeak stress-strain curve of coal and rock.

(2) The $E_{\mathrm{e}} / E_{\mathrm{d}}$ can be used as an index to evaluate the coal and rockburst strength, and the smaller the $E_{\mathrm{e}} / E_{\mathrm{d}}$, the greater the rockburst strength. In addition, for the same type of rock, with the increase of confining pressure, the $E_{\mathrm{e}} / E_{\mathrm{d}}$ increases, that is, the rockburst strength decreases. So, the greater the support strength provided to the roadway surrounding rock surface, the smaller the failure degree of rockburst.

(3) With the increase of confining pressure, after peak strength, the elastic energy of coal specimen decreases slowly and the dissipated energy increases slowly, indicating that the increase of confining pressure can effectively limit the energy dissipation and release after coal specimen failure. So, in the insitu engineering practice, it is an important measure to improve the surface restraint and support strength of coal roadway for reducing the occurrence intensity and probability of rockburst.

(4) The combined measures of "the mining of double liberating seam + the implementation of large-diameter pressure relief borehole in advance of working face" is the very effective way to eliminate rockburst accidents of working face in protected coal seam and provide the theoretical guidance and engineering reference for the safe mining of rockburst mine.

\section{Data Availability}

The data used to support the findings of this study are available from the corresponding author upon request.

\section{Conflicts of Interest}

The authors declare that they have no conflicts of interest.

\section{Acknowledgments}

This research was supported by the National Key R\&D Program of China (Grant no. 2018YFC0604700), the National Natural Science Foundation of China (Grant no. 51474134), and the Natural Science Innovation Foundation of Inner Mongolia University of Science and Technology (Grant no. 2019QDL-B25).

\section{References}

[1] S. J. Chen, W. J. Guo, H. Zhou, B. T. Shen, and J. B. Liu, "Field investigation of long-term bearing capacity of strip coal pillars," International Journal of Rock Mechanics and Mining Sciences, vol. 70, pp. 109-114, 2014.

[2] T. B. Zhao, W. Y. Guo, Y. L. Tan, Y. C. Yin, L. S. Cai, and J. F. Pan, "Case studies of rock bursts under complicated geological conditions during multi-seam mining at a depth of 800 m," Rock Mechanics and Rock Engineering, vol. 51, no. 5, pp. 1539-1564, 2018.
[3] P. Wang, L. S. Jiang, J. Q. Jiang, P. Q. Zheng, and W. Li, "Strata behaviors and rock burst inducing mechanism under the coupling effect of a hard, thick stratum and a normal fault," International Journal of Geomechanics, vol. 18, no. 2, Article ID 04017135, 14 pages, 2018.

[4] Y. C. Yin, T. B. Zhao, Y. B. Zhang et al., "An innovative method for placement of gangue backfilling material in steep underground coal mines," Minerals, vol. 9, no. 2, Article ID 107, 14 pages, 2019.

[5] N. Li and R. Jimenez, "A logistic regression classifier for longterm probabilistic prediction of rock burst hazard," Natural Hazards, vol. 90, no. 1, pp. 197-215, 2018.

[6] Q. X. Qi, Y. Z. Li, S. K. Zhao et al., "Seventy years development of coal mine rockburst in China: establishment and consideration of theory and technology system," Coal Science and Technology, vol. 47, no. 9, pp. 1-40, 2019.

[7] J. F. Pan, Y. Ning, D. B. Mao, H. Lan, T. T. Du, and Y. W. Peng, "Theory of rockburst start-up during coal mining," Chinese Journal of Rock Mechanics and Engineering, vol. 31, no. 3, pp. 586-596, 2012.

[8] M. T. Zhang, "Instability theory and mathematical model for coal/rock bursts," Chinese Journal of Rock Mechanics and Engineering, vol. 6, no. 3, pp. 197-204, 1987.

[9] G. A. Zhu, L. M. Dou, H. S. Wang, H. Y. Liu, and G. W. Dong, "Back analysis of rock burst risk and fault slip due to mining in the island panel along fault: a case study of island panel 3108 in Chaoyang coal mine," Journal of China Coal Society, vol. 45, no. 2, pp. 533-541, 2020.

[10] T. W. Shi, Y. S. Pan, A. W. Wang, and L. P. Dai, "Classification of rock burst in coal mine based on energy storage and release bodies," Journal of China Coal Society, vol. 45, no. 2, pp. 524-532, 2020.

[11] S. Q. He, D. Z. Song, X. Q. He et al., "Coupled mechanism of compression and prying-induced rock burst in steeply inclined coal seams and principles for its prevention," Tunneling \& Underground Space Technology, vol. 98, Article ID 103327, 22 pages, 2020.

[12] L. S. Jiang, P. Kong, P. P. Zhang et al., "Dynamic analysis of the rock burst potential of a longwall panel intersecting with a fault," Rock Mechanics and Rock Engineering, vol. 53, no. 4, pp. 1737-1754, 2020.

[13] M. Zhang and F. X. Jiang, "Rock burst criteria and control based on an abutment-stress-transfer model in deep coal roadways," Energy Science \& Engineering, vol. 8, no. 8, pp. 2966-2975, 2020.

[14] J. H. Liu, M. H. Zhai, X. S. Guo, F. X. Jiang, G. J. Sun, and Z. W. Zhang, "Theory of coal burst monitoring using technology of vibration field combined with stress field and its application," Journal of China Coal Society, vol. 39, no. 2, pp. 353-363, 2014.

[15] W. L. Zhang, X. C. Qu, L. Chen et al., "Fracture analysis of multi-hard roofs based on micro seismic monitoring and control techniques for induced rock burst: a case study," Arabian Journal of Geosciences, vol. 12, no. 24, p. 14, Article ID 784, 2019.

[16] S. T. Zhu, Y. Feng, F. X. Jiang, and J. H. Liu, "Mechanism and risk assessment of overall-instability-induced rockbursts in deep island longwall panels," International Journal of Rock Mechanics and Mining Sciences, vol. 106, pp. 342-349, 2018.

[17] F. Cui, S. Dong, X. P. Lai, J. Q. Chen, J. T. Cao, and P. F. Shan, "Study on rule of overburden failure and rock burst hazard under repeated mining in fully mechanized top-coal caving face with hard roof," Energies, vol. 12, no. 24, Article ID 4780, 16 pages, 2019. 
[18] J. F. Zhang, F. X. Jiang, S. T. Zhu, and L. Zhang, "Width design for gobs and isolated coal pillars based on overall burst-instability prevention in coal mines," Journal of Rock Mechanics and Geotechnical Engineering, vol. 8, no. 4, pp. 551-558, 2016.

[19] W. Cai, L. M. Dou, G. Y. Si et al., "A new seismic-based strain energy methodology for coal burst forecasting in underground coal mines," International Journal of Rock Mechanics and Mining Sciences, vol. 123, Article ID 104086, 11 pages, 2019.

[20] Z. J. Wen, X. Wang, Y. L. Tan, H. L. Zhang, W. P. Huang, and Q. H. Li, "A study of rockburst hazard evaluation method in coal mine," Shock and Vibration, vol. 2016, Article ID 8740868, 9 pages, 2016.

[21] S. T. Zhu, Y. Feng, and F. X. Jiang, "Determination of abutment pressure in coal mines with extremely thick alluvium stratum: a typical kind of rockburst mines in China," Rock Mechanics and Rock Engineering, vol. 49, no. 5, pp. 1943-1952, 2016.

[22] Z. C. Wang and W. R. Bian, "Analysis of pressure relief effect on the protective layer of hard roof and extra-thickness coal seam mining," Geotechnical and Geological Engineering, vol. 37, no. 1, pp. 163-172, 2019.

[23] B. W. Ma, Z. G. Deng, S. K. Zhao, and S. G. Li, "Analysis on the mechanism and influencing factors of drilling pressure relief to prevent rock burst," Coal Science and Technology, vol. 48, no. 5, pp. 35-40, 2020.

[24] W. Y. Guo, Q. H. Gu, Y. L. Tan, and S. C. Hu, "Case studies of rock bursts in tectonic areas with facies change," Energies, vol. 12, no. 7, pp. 1-11, 2019.

[25] J. F. Pan, Q. X. Qi, S. H. Liu, S. W. Wang, W. T. Ma, and X. C. Kang, "Characteristics, types and prevention and control technology of rock burst in deep coal mining in China," Journal of China Coal Society, vol. 45, no. 1, pp. 111-121, 2020.

[26] L. M. Dou, J. L. Kan, X. W. Li, Y. J. Qi, J. Z. Bai, and M. H. Liu, "Study on prevention technology of rock burst by break-tip blasting and its effect estimation," Coal Science and Technology, vol. 48, no. 1, pp. 24-32, 2020.

[27] S. C. Zhang, Y. Y. Li, B. T. Shen, X. Z. Sun, and L. Q. Gao, "Effective evaluation of pressure relief drilling for reducing rock bursts and its application in underground coal mines," International Journal of Rock Mechanics and Mining Sciences, vol. 114, pp. 7-16, 2019.

[28] Z. H. Li, L. Y. Zhu, W. L. Yin, and Y. F. Song, "Study on monitoring rock burst through drill pipe torque," Shock and Vibration, vol. 2015, Article ID 371948, 8 pages, 2015.

[29] Z. Z. Zhang and G. Feng, "Research on nonlinear characteristics of rock energy evolution under uniaxial compression," Chinese Journal of Rock Mechanics and Engineering, vol. 31, no. 6, pp. 1198-1207, 2012.

[30] Z. Q. Chen, T. B. Li, G. Q. Chen, and C. C. Ma, "Experimental study on energy evolution of sandstone under different stress paths," Engineering Mechanics, vol. 33, no. 6, pp. 120-128, 2016.

[31] D. Huang, Q. Tan, and R. Q. Huang, "Mechanism of strain energy conversion process for marble damage and fracture under high stress and rapid unloading," Chinese Journal of Rock Mechanics and Engineering, vol. 31, no. 12, pp. 24832493, 2012.

[32] D. Huang, Q. Tan, and R. Q. Huang, "Fractal characteristics of fragmentation and correlation with energy of marble under unloading with high confining pressure," Chinese Journal of Rock Mechanics and Engineering, vol. 31, no. 7, pp. 1379-1389, 2012. 